\title{
Geomapping of trematode-induced granulomatous anterior uveitis - a newly identified cause of blindness among children in the Pudukkottai district of the Tamil Nadu State, India
}

\author{
Duraisamy Jayakumar ${ }^{1}$, Sivakumar Kavitha ${ }^{1}$, Sivakumar Rathinam ${ }^{2}$, Gnanam Vasanthi ${ }^{1}$ \\ ${ }^{1}$ Division of Geo-Informatics, Department of Physics, Lady Doak College, Madurai, 625 002, India; \\ ${ }^{2} P G$ Institute of Ophthalmology, Aravind Eye Hospital, 1, Anna Nagar, Madurai, 625 020, India
}

\begin{abstract}
There is evidence that a specific type of allergic conjunctive-uveal granuloma reported from South India could be due to infection by a trematode parasite. In these patients, the histopathological examination of the eye reveals a zonal granulomatous inflammation with purulent material including structures displaying evidence of trematode infection. To investigate this further, medical records describing such cases in the Pudukkottai district, Tamil Nadu State, India, covering the period 2001-2005, were collected. Since trematodes require a snail intermediate host for completing the life cycle, ponds frequently used for bathing in the area were inspected to identify a possible culprit. The hypothesis that ponds with snail habitats could be the source of infection was supported by the finding of a positive correlation between the geographical distribution of patients' residencies and the location of such ponds. Geographic information systems (GIS) were used to study the spatial distribution of ponds and patients, while satellite-based remote sensing (RS) was applied to attempt finding a parameter characteristic for ponds with snail habitats that could facilitate risk-identification over larger areas. It was found that ponds carrying risk could be differentiated from others through analysis of their spectral surface properties. This pond classification approach, confirmed by field visits, could thus become a useful tool for the location of snail habitats constituting risk as predicted.
\end{abstract}

Keywords: trematode infection, granulomatous anterior uveitis, Melanoides tuberculata, geographical information systems, remote sensing, India.

\section{Introduction}

Based on anamnestic and clinical findings in patients reporting to the Aravind Eye Hospital at Madurai in South India, one of the few full-time uveitis clinics in India, a new cause of intraocular inflammation in children has been recognized (Rathinam et al., 2001, 2002). The 2001 paper constitutes the very first report of trematode-associated granulomatous uveitis, i.e. inflammation of the middle

Corresponding author:

Jayakumar Duraisamy

Division of Geo-Informatics

Department of Physics, Lady Doak College

Madurai, 625 002, India

Tel. +91 452253 7599; Fax +91 4522523585

Email: drdjk2006@gmail.com layer of the eye, and describes a cluster of such cases in a coastal village. The patients, primarily young boys, showed the typical histologic findings consisting of conjunctival nodules with a distinct zonal granulomatous inflammation displaying a distinct doublelayer tegument, typical of trematodes. Apart from this histopathological picture, other investigations such as fundus fluorescein angiography (FFA), ultrasonography (USG), optical coherence tomography (OCT) and ultrasound bio microscopy (UBM) were performed to confirm the diagnosis of a newly recognized disease which often leads to blindness in those infected.

Trematode worms belong to the subclass Digenea, a group made up of more than 40,000 species with diverse morphologies and life cycles (Orihel and Ash, 1995). All trematodes are parasitic and most of 
them are endoparasites of vertebrates. The majority have complex life cycles with larval stages parasitizing one or more species before settling as adults in the definite host. These parasites, e.g. the liver flukes and the blood flukes that cause schistosomiasis (Chen, 2002), strongly impact human populations in many parts of the world.

Vertebrate trematode infections are usually acquired after ingesting the infective forms, most often by drinking or swallowing infected water while swimming (Littlewood and Bray, 2000) or by transmission from wet hands to the mouth or nose (Poulin and Morand, 2005). Some of these intermediate forms of this type of parasite can also penetrate the skin as in schistosomiasis (Chen, 2002). Other parasites of interest in this connection include Opisthorchis sinensis (Dundee and Paine, 1977) and Philophthalmus sp. (Russo, 1973). Interestingly, it has been shown that the latter organism parasitizes the eye of birds. The first human case of Philophthalmus infection was found in Thailand (Waikagul et al., 2006).

Although there is no direct evidence for the identity of the intermediate host for the trematode species causing the granulomatous anterior uveitis, it could well be Melanoides tuberculata Müller, 1774 (Gastropoda: Thiaridae), which is commonly found in the ponds in Pudukkottai. This mollusk is native to a broad geographical area stretching from Morocco in the west to Indonesia in the East, including Madagascar, Saudi Arabia, Iran, Pakistan, India and southern China (Clench, 1969; Neck, 1985). In addition, Thiengo et al. (2001) have reported the occurrence of this species infected with pleurolophocercous cercariae in two municipalities of the state of Rio de Janeiro, Brazil. M. tubercula$t a$ is monitored in many places because they can serve as the intermediate host for a large number of trematodes including Paragonimus and Chlonorchis (Malek and Cheng, 1974; Roberts and Janovy, 1998). M. tuberculata is also very tolerant regarding the salinity of the water and they have high tolerance towards variations in $\mathrm{pH}$ explaining the present ubiquity of this species. The snail is typically found in shallow, slow running water of 0.6-1.2 m depth but it has also been reported from deeper levels. M. tuberculata prefers a substrate consisting of soft mud and sand but there are also claims that it prefers a substrate composed largely of rocks (Murray, 1975). It is very resistant to low oxygen levels (Neck, 1985) and hides during the day by borrowing into the mud (Livshits and Fishelson, 1983). It is mostly active at night in areas rich in detritus and silt behind overhanging stems and protruding roots of bank vegetation such as Eragrotis and Lysimachia (Dundee and Paine, 1977). M. tuberculata occurrs almost exclusively in shady and humanimpacted areas usually associated with fine and coarse particulate organic matter (Rocha-Miranda and Martins-Silva, 2006).

Since the clustering of infected children in this part of India seemed to be correlated to swimming and bathing in fresh-water ponds, it was felt that it would be useful to apply geographical information system (GIS). Public health resources, diseases and events can be mapped in relation to their environment and this information, when presented as a joint panorama, is a powerful support for the monitoring of epidemics (Johnson and Johnson, 2001). It can also facilitate the mapping of the impact zone around a vector-breeding site where control and surveillance need to be strengthened. Besides GIS, remote sensing (RS) is a useful tool for disease surveillance and control, particularly with reference to vector-borne diseases, which are often found in poor populations living in remote areas. This approach meets the demands of rapid outbreak response by supporting prompt case location, rapid communication, and mapping of epidemic dynamics. Modeling of infectious diseases with the aid of data from GIS and RS observations is now commonplace. Examples include trypanosomiasis (Kitron et al., 1996; Rogers et al., 1997), rift valley fever (Linthicum et al., 1999), malaria (Hay et al., 1998; Thomson et al., 2003), Lyme disease (Dister et al., 1997; Kitron and Kazmierczak, 1997) and schistosomiasis (Seto et al., 2002; Xu, 2003).

This study was not only designed to attempt find- 
ing evidence for the possible origin of the trematode-induced granulomatous anterior uveitis but also to investigate the possibilities for risk-mapping in the Pudukkottai district. The association of the disease with a trematode parasite prompted the investigation in the direction of ponds with snail habitats where an intermediate host for this infection might exist, especially if the ponds are frequently used for swimming.

\section{Materials and methods}

\section{Study site}

The Pudukkottai district is situated near the centre of the Tamil Nadu State in South India (Fig. 1). It is surrounded by the Tiruchirappalli district in the north, the Sivagangai and Ramnad districts in the west, the Thanjavur district in the north-east and the Bay of Bengal in the south-east. The district covers an area of $4,663 \mathrm{~km}^{2}$ between latitudes $9^{\circ} 50^{\prime}$ and $10^{\circ} 44^{\prime}$ North and longitudes $78^{\circ} 25^{\prime}$ and $79^{\circ} 15^{\prime}$ East and consists mainly of an undulating plain, interspersed with rocky hills in the southwest with an average elevation of $100 \mathrm{~m}$ (328 feet). The minimum and maximum temperatures range between $20^{\circ} \mathrm{C}$ and $32^{\circ} \mathrm{C}$. The annual rainfall is $800 \mathrm{~mm}$ with the northeast monsoon providing the major source of rain. Although the earth is nowhere particularly fertile, in fact in many parts barren, agriculture is still the major activity. However, as the land is prone to drought, crops depend on rains and ground water. The rivers carry water only in the rainy season but there are close to 600 lakes, which irrigate the farmlands. In addition, there is a large number of ponds scattered around the district. The coastal part consists of a narrow, $35 \mathrm{~km}$ long region of sandy beach along the delta of the Vellar River. There are 15 coastal villages and people here are engaged in fishing. There are also inland fisheries but these are operated only at a modest level due to the general lack of water.

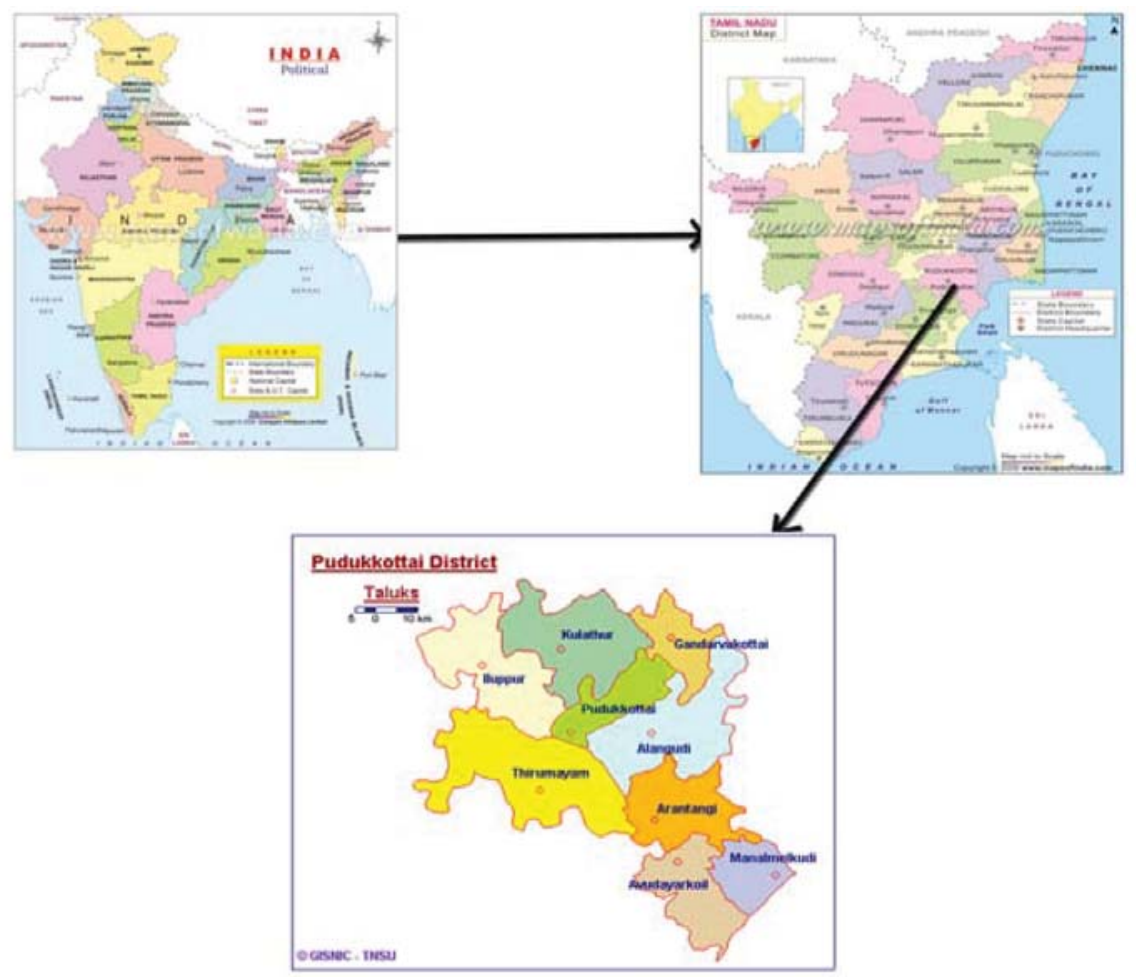

Fig. 1. The study area and its location on the Indian subcontinent. 


\section{Study design}

The project was carried out stepwise along two arms: one geared at retrieving data on patients with trematode-induced granulomatous anterior uveitis, investigating suspected sources of infection and georeferencing the information, the other utilizing $\mathrm{RS}$ using satellite imagery for the prediction of infected ponds based on differences in spectral reflectance.

\section{Data collection}

Information regarding patients with the disease under study was collected from the Uvea service of Aravind Eye Hospital for a period of five years (2001 to 2005). The individual patients were visited and questionnaires were used to collect information about the socio-economic status, the nearest water source, its distance from the residence, surrounding snail habitats (if known) and the patient's personal swimming habits. The home of each individual patient and the nearby ponds frequently used for swimming and bathing were geo-located during the visits to the field using a global positioning system (GPS) instrument. Water bodies, rivers and streams were digitized and the geo-referenced residences of every infected patient were plotted onto this map. The ponds were investigated with reference to the presence of M. tuberculata snails. The snails found were sampled and subjected to microscopic examination as well as prompted to release cercariae under laboratory conditions.

\section{Identification of risk areas by $R S$}

The analysis presented here is based on a sample area of satellite imagery covering a surface area of $23.5 \mathrm{~km}^{2}$. The "eye" was a LISS-IV camera onboard the Indian Earth Resource Satellite "RESOURCESAT-1" (IRS-P6) (http://envisat.esa .int/object/index.cfm?fobjectid=3746) that can be operated, either in pancromatic or multi-spectral mode, with a resolution of $5.8 \mathrm{~m}$. The present study used multi-spectral imagery from this sensor (IRS
LISS-IV MX) from February 2006 to identify suspected snail habitats, i.e. ponds with the type of plants suitable for the Melanoides snail described above.

Classification of the IRS-P6 images was based on the difference in spectral reflectance (five training signatures) between ponds with plants making them possible snail habitats and ponds without this characteristic. Supervised classification was performed using maximum-likelihood classification (Foody et al., 1992; Seto et al., 2002; Xu et al., 2004). Each pixel in the image was compared against two training signatures to classify the image into possible snail habitats and other areas. To tease out heterogeneity, a multivariate ISODATA cluster analysis was performed as described by Tou and Gonzalez (1977) and Seto et al. (2002). The findings were confirmed by field visits.

This imagery can be presented as a classified picture (Fig. 3c) showing the risk-carrying ponds in red against the black safe areas. Figure $3 \mathrm{a}$ is the full unclassified image and Figure $3 b$ shows the first step of classification, still including more information than the completely "cleaned" Figure 3c.

Risk related to water contact in ponds, was investigated by snail sampling and subsequent cercarial shedding in the laboratory.

After field verification, a thematic map depicting the intensity of the disease/vector system was generated. Buffer analysis was performed to map the impact zones of vector breeding sites and multi-ring buffer analysis was carried out for a perimeter of 2 $\mathrm{km}$ to identify the spatial distribution of trematodeinfected epidemic areas. Figure 2 shows an example of this approach.

For validation, the same set of supervised maximum-likelihood classification and ISODATA clustering was performed using signatures referring to infested and non-infested ponds in that area of the Pudukkottai district and the results confirmed by field visits. With this methodology, based on a trial basis for nine ponds, an overall accuracy of $80 \%$ was obtained in predicting which ponds were really snail-infested. 


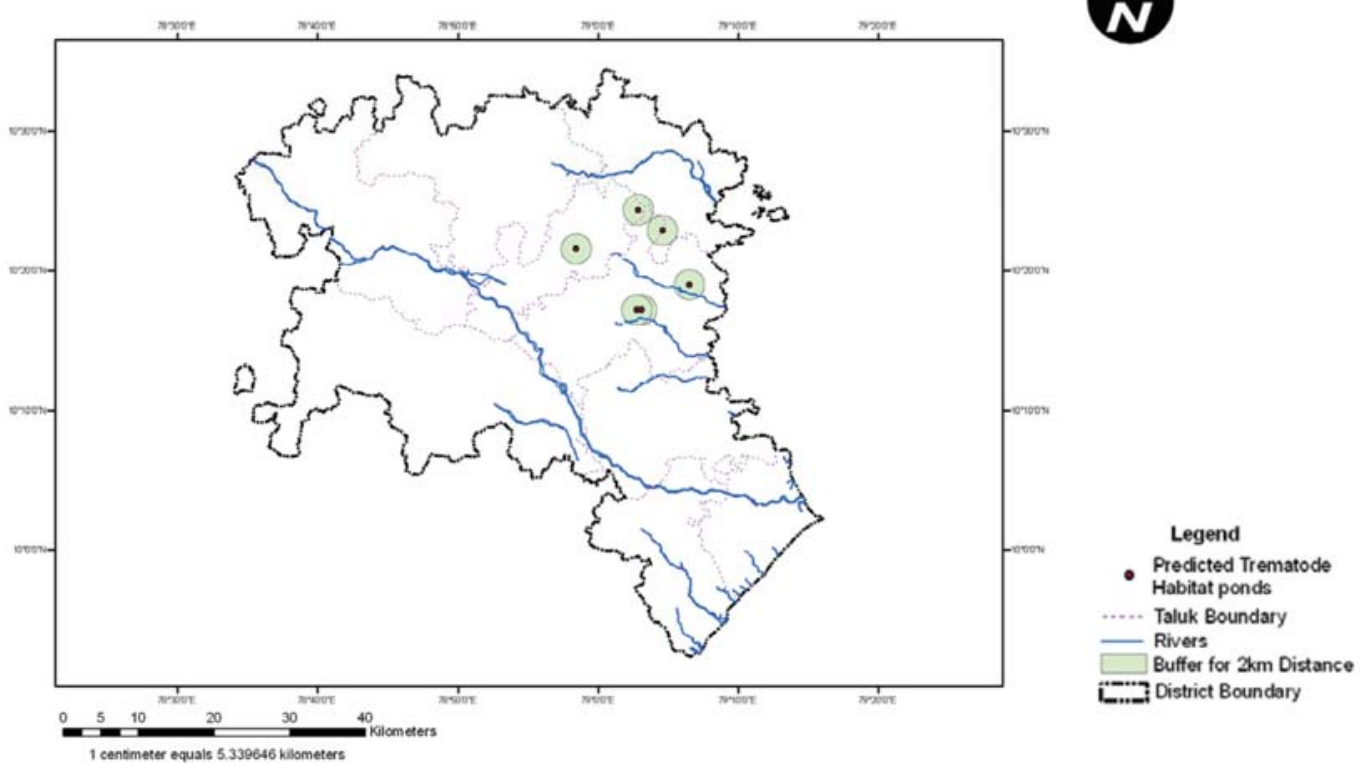

Fig. 2. Examples of predicted identified trematode habitat ponds with $2 \mathrm{~km}$ distance buffer zone.

IRS LISS-4 MX Satellite Imagery

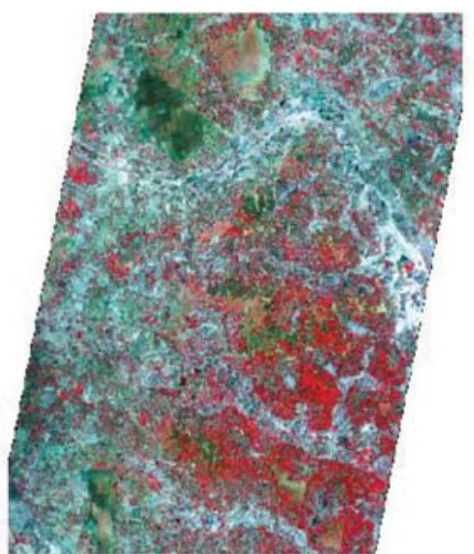

a)
Classified IRS LISS-4 MX Imagery

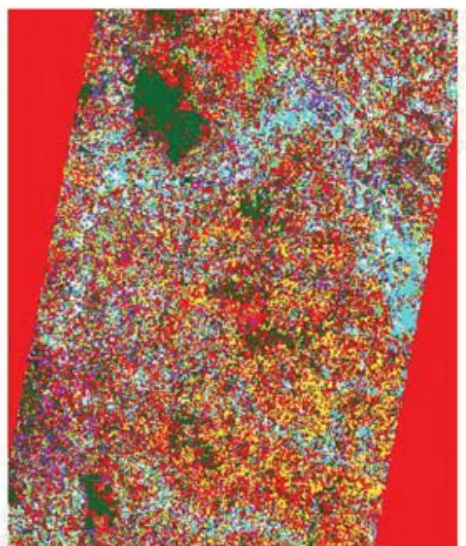

b)

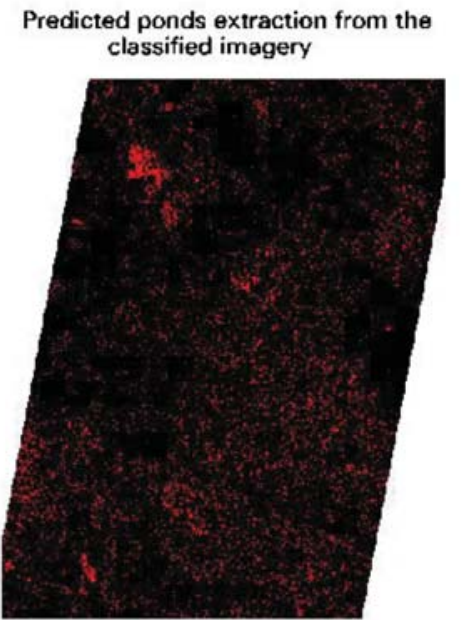

c)

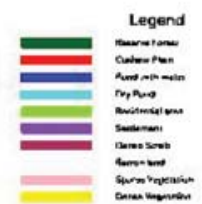

Fig. 3. Classification of snail habitats based on ISODATA and maximum likelihood algorithms. The figure represents a stepwise classification procedure ending with a picture (c) of all ponds of potential risk. 


\section{Results}

In the hospital, records of a total of 39 individuals with trematode-induced granulomatous anterior uveitis were found. Three were adults, aged 40, 42 and 61 years, while the remainder of the patients were children from three to 16 years old, 29 male and seven female. It was noted in the records that the patients had a history of itching and swelling of the buccal mucosa after swimming in the local river or pond prior to developing the disease. From the spatial distribution of these patients it was found that the distribution covered seven taluks. The infection was more severe in the cases living near the coastal area.

On-site observation of ponds used by children for swimming revealed several freshwater gastropods around the edges and also on plants in deeper water. The snail habitats were generally seen in areas shaded by overhanging branches and protruding roots where the water was polluted by particulate organic matter. Although different gastropods were observed, the populations were dominated by M. tuberculata (Fig. 4). Collected snail samples subjected to hatching in the laboratory produced cercariae as shown in Fig. 5.

After the water bodies present in the area had been digitized and the geo-referenced residences of the patients plotted onto this map, the spatial distribution of the disease in the district became evident (Fig. 6).

The sample area analysis revealed five infected ponds. Based on supervised RS classification another 15 possibly infected ponds were predicted as they showed similar reflectance characteristics as that of the snail-infested ponds in the sample area. Sampling followed by cercarial shedding showed that six of them were trematode-infected snail habitats. Through field visits it was learnt that infected patients live around these ponds and that they also use them for swimming and bathing. Another four ponds were not used. No infected cases where identified there or around the remaining five ponds.

Based on supervised RS classification of the entire Pudukkottai district consisting of 15 imagery satel-

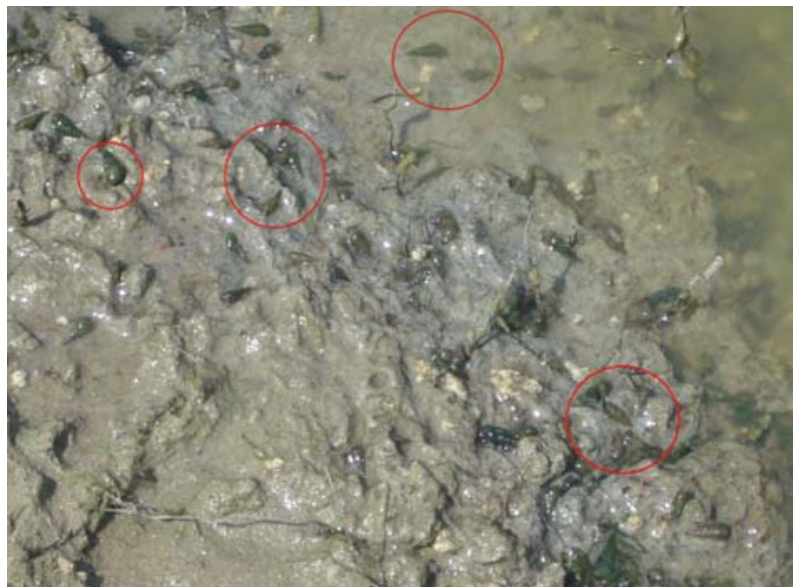

Fig. 4. A sample of M. tuberculata snails from the bottom sediment of an infested pond.

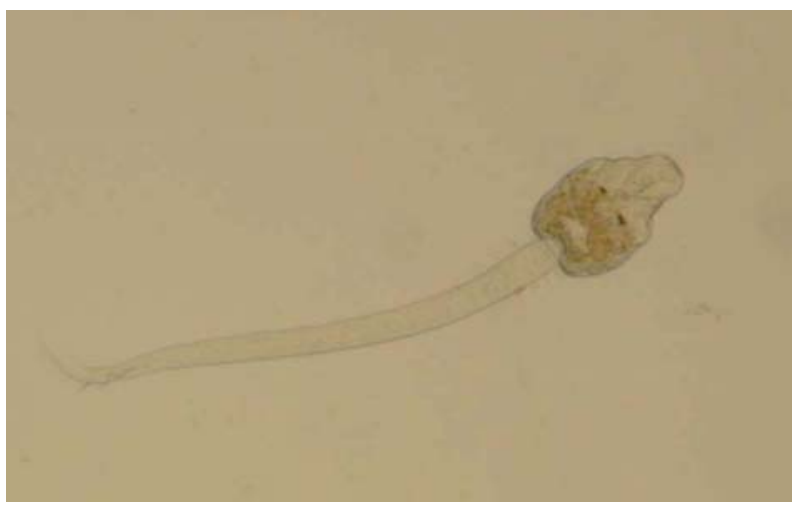

Fig. 5. A cercaria released by shedding from a M. tuberculata snail in the laboratory.

lite scenes, there is possibility of another, possibly infected, 225 ponds. The risk-areas, which should be more closely investigated, are Vandanviduthi, Chettividuthi, Kupliyankottai, Nainankollai, Periyavadi, Kondayanteru, Pulichankadu, Mangadu, Ponankulam, Nembakkottai, Korumbarkottai, Kallalankudi and Ayyapatti.

\section{Discussion}

Because mollusks are required as the first (or only) intermediate host in all trematode lifecycles, there is a high probability that they also serve as the intermediate host for the human trematode-associated 


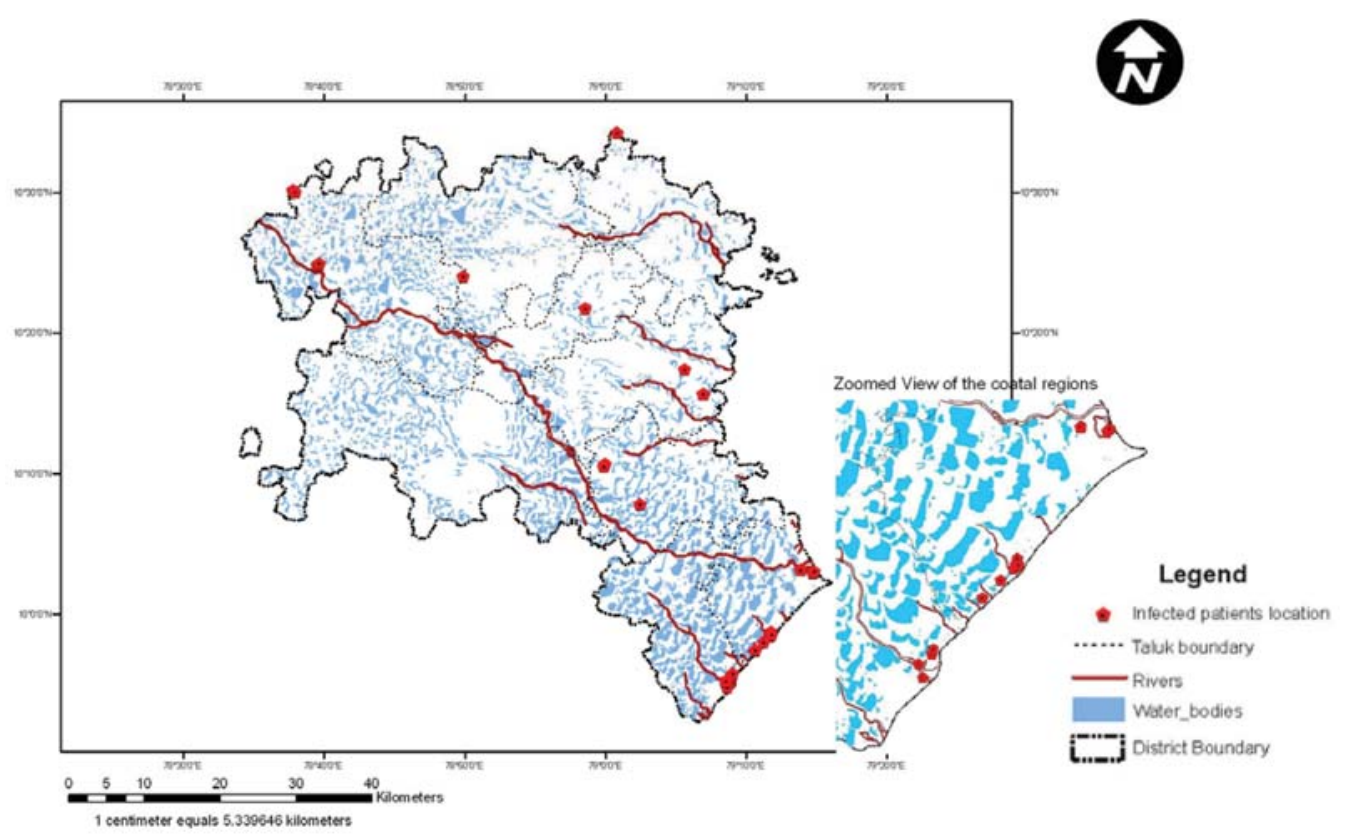

Fig. 6. Location of infected patients in the Pudukkottai district.

anterior granulomatous uveitis investigated here. From the questionnaire, collected at the time of field survey it was observed that all infected ponds situated near to patients' residencies (and also frequently used by them) are surrounded by dense macropytes. These ponds provide the conditions (ephiphytic algae, fine detritus and organic matter in the bottom sediments) particularly suitable for the smaller prosobranch species, M. tuberculata (Hunter, 1980; Reavell, 1980; Madsen, 1992). The study has shown that the risk is associated with bathing in this type of pond, which indicates that the link could be cercariae released from this snail. However, further research is needed to identify exactly which snail and trematode species are implicated.

Cercariae select microhabitats with a defined light intensity. For example, the cercariae of human schistosomes leave their intermediate hosts in the middle of the day and accumulate in the uppermost water layers, whereas those from parasites of grounddwelling invertebrates orientate towards the bottom. Since the time of day that the cercariae occupy the microhabitats is correlated to the habits of the definite host, and most of the infected cases were children swimming at the surface around noon time, they would only be targeted if it can be shown that cercarial release from the $M$. tuberculata snails coincides with that space and time. This would suggest that the infected subjects were targeted by the cerariae of a specific trematode parasite not previously known to infect humans. The other alternative, i.e. that the patients were accidentically infected by other species adapted to various animals, is supported by the fact that there were a relatively low number of patients in the hospital records of a 5year period, while $M$. tuberculata is widely spread. In addition, swimmer's itch i.e. the dermatitis in humans exposed to cercariae of trematodes targeting birds (Nash, 1998), is reminiscent of the itching and swelling of the buccal mucosa reported by our patients prior to developing the granulomatous uveitis. However, the question if trematode-associated anterior granulomatous uveitis represents a targeted or an accidental infection cannot be solved without further laboratory and clinical studies.

To produce predictive estimates of the spatial dis- 
tribution of trematode infection, we focused on the characteristics that support snail habitats, relying on field studies to validate the accuracy of our RS classification work. In this area the infection seems to be related to the presence of certain pounds and agricultural practices, which influence human infection through water contact.

Very few schistosome species produce cercariae capable of penetrating human skin and they are the cause of all forms of human schistosomiasis, which affects about 200 million people globally. Peculiarly, apart from a few geographically very limited areas this disease does not exist in India. The observed presence of the nodules in the conjunctiva and eyelids of the patients under study, and the absence of such nodules elsewhere in the infected patients' skin, suggest that these cercariae belong to a trematode species that can penetrate the conjunctiva but not the epidermis.

\section{Acknowledgements}

We would like to acknowledge the University Grants Commission of India for providing the funding of this work, the Aravind Eye Hospital (Madurai) for collaborating work and Remote Sensing and GIS laboratory (Funded by ISRO, India) of the PG and Research Department of Physics, Lady Doak College, Madurai.

\section{References}

Chen MG, 2002. The prevalence situation and the prevention and cure progress of global schistosomiasis. Chin J Schisto Control 14, 81-83.

Clench WJ, 1969. Melanoides tuberculata (Müller) in Florida. Nautilus 83, 72.

Dister SW, Fish D, Bros S, Frank DH, Wood BL, 1997. Landscape characterization of peridomestic risk for Lyme disease using satellite imagery. Am J Trop Med Hyg 57, 687-692.

Dundee DS, Paine A, 1977. Ecology of the snail Melanoides tuberculata (Müller), intermediate host of the human liver fluke (Opisthorchis sinensis) in New Orleans, Louisiana. Nautilus 91, 17-20.
Foody GM, Campbell NA, Trodd NM, Wood TF, 1992. Derivation and applications of probabilistic measures of class membership from the maximum-likelihood classification, Photogramm Eng Remote Sensing 58, 1335-1341.

Hay SI, Snow RW, Rogers DJ, 1998. From predicting mosquito habitat to malaria seasons using remotely sensed data: practice, problems and perspectives. Parasitol Today 14, 306-313.

Johnson CP, Johnson J, 2001. GIS: a tool for monitoring and management of epidemics. Map India 2001 Conference, New Delhi, India.

Kitron U, Kazmierczak JJ, 1997. Spatial analysis of the distribution of Lyme disease in Wisconsin. Am J Epidemiol $145,558-566$.

Kitron U, Otieno LH, Hungerford LL, Odulaja A, Brigham WU, Okello OO, Joselyn M, MohamedAhmed MM, Cook E, 1996. Spatial analysis of the distribution of tsetse flies in the Lambwe Valley, Kenya, using Landsat TM satellite imagery and GIS. J Anim Ecol 65, 371-380.

Linthicum KJ, Anyamba A, Tucker AJ, Kelley PW, Myers MF, Peters CJ, 1999. Climate and satellite indicators to forecast Rift Valley fever epidemics in Kenya. Science 285, 397-400.

Littlewood DTJ, Bray, RA, 2000. "The digenea", interrelationships of the platyhelminthes, 1 . Systematics association special volume 60, CRC, 168-185.

Livshits G, Fishelson L, 1983. Biology and reproduction of the freshwater snail Melanoides tuberculata (Gastropoda: Prosobranchia) in Israel. Isr J Zool 32, 21-35.

Malek EA, Cheng TC, 1974. Medical and economic malacology. Academic Press, London, UK, 398 pp.

Murray HD, 1975. Melanoides tuberculata (Müller), Las Morras Creek, Bracketville, Texas. Bull Am Malacol Union, 43.

Nash TE, 1998. Schistosomiasis and other trematode infections. In: Helminthic infections. Harrison's principles internal medicine. Fauci AS, Braunwald E, Isselbacker KJ et al. (Eds) Vol. 1, McGraw-Hill, New York, USA, pp. 1217-1224.

Neck RW, 1985. Melanoides tuberculata in extreme Southern Texas. Texas Conchologist 21, 150-152.

Orihel TC, Ash LR, 1995. Parasites in human tissues. ASCP Press, Chicago, USA, pp. 255-257.

Poulin R, Morand S, 2005. Parasite biodiversity. Smithsonian, 216. Hong Kong University Press, Hong Kong.

Rathinam SR, Fritsche TR, Srinivasan M, Vijayalakshmi P, 
Read RW, Gautom R, Namperumalsamy P, Rao NA, 2001. An outbreak of trematode-induced granulomas of the conjunctiva. Ophthamology 108, 1223-1229.

Rathinam SR, Usha KR, Rao NA, 2002. Presumed trematode-induced granulomatous anterior uveitis: a newly recognized cause of intraocular inflammation in children from South India. Am J Opthamol 133, 773-779.

Roberts L, Janovy JR, 1998. J. Foundations of Parasitology. Wm. C. Brown, Boston, USA.

Rocha-Miranda F, Martins-Silva MJ, 2006. First record of the invasive snail Melanoides tuberculatus (Gastropoda: Prosobranchia: Thiaridae) in the Paranã River basin, GO, Brazil. Braz J Biol 66, 1109-1115.

Rogers DJ, Hay SI, Packer MJ, Wint GRW, 1997. Mapping land-cover over large areas using multispectral data derived from the NOAA-AVHRR: a case study of Nigeria. Int J Remote Sens 18, 3297-3303.

Seto E, Xu B, Liang S, Gong P, Wu WP, Davis G, Qiu DC, $\mathrm{Gu}$ XG, Spear R, 2002. The use of remote sensing for predictive modeling of schistosomiasis in China. Photogramm Eng Remote Sensing 68, 167-174.

Thiengo SC, Fernandez MA, Boaventura MF, Grault CE, Silva HF, Mattos AC, Santos SB, 2001. Freshwater snails and schistosomiasis mansoni in the State of Rio de Janeiro,
Brazil: I - Metropolitan mesoregion. Mem Inst Oswaldo Cruz 96, 177-184.

Thomson M, Indeje M, Connor S, Dilley M, Ward N, 2003. Malaria early warning in Kenya and seasonal climate forecasts. Lancet 361, 1705-1706.

Tou JT, Gonzalez RC, 1977. Pattern recognition principles, applied mathematics and computation No. 7, AddisonWesley Pub. Co., Reading, Massachusetts, USA, 377 pp.

Waikagul J, Dekumyoy P, Yoonuan T, Praevanit R, 2006. Conjunctiva philopthalmosis: a case report in Thailand. Am J Trop Med Hyg 74, 848-849.

$\mathrm{Xu} \mathrm{B,} \mathrm{2003.} \mathrm{Spatio-temporal} \mathrm{modeling} \mathrm{with} \mathrm{GIS} \mathrm{and} \mathrm{remote}$ sensing for schistosomiasis control in Sichuan, China, Ph.D. dissertation, University of California, Berkeley, California, USA $117,37 \mathrm{pp}$.

Xu B, Gong P, Biging G, Liang S, Seto E, Spear R, 2004. Snail density prediction for schistosomiasis control Using Ikonos and ASTER images. Photogramm Eng Remote Sensing 70, 1285-1294.

Zhou XN, Lin DD, Yang HM, Chen HG, Sun LP, Yang GJ, Hong QB, Brown L, Malone JB, 2002. Use of Landsat TM satellite surveillance data to measure the impact of the 1998 flood on snail intermediate host dispersal in the lower Yangtze River Basin. Acta Trop 82, 193-198. 